\title{
APRENDIZAGEM E DESENVOLVIMENTO DE JOVENS E ADULTOS ALFABETIZADOS A PARTIR DE UMA ABORDAGEM HISTÓRICO-CULTURAL
}

\author{
MARIA CLARISSE VIEIRA' \\ ORCID https://orcid.org/0000.0001-5924-0488 \\ LUCIANA DE OLIVEIRA PINTO' \\ ORCID https://orcid.org/0000-0002-5841-9379
}

I Universidade de Brasília, Faculdade de Educação, Brasília, DF, Brasil.

RESUMO: Este artigo apresenta os resultados de pesquisa que teve como objetivo investigar as contribuições que a aprendizagem da leitura e da escrita propicia ao desenvolvimento de jovens e adultos, bem como significados por eles atribuídos ao seu processo de alfabetização, tendo como base a abordagem histórico-cultural de Bakhtin, Vigotski e Leontiev e o materialismo histórico e dialético de Marx e Engels. O procedimento metodológico da referida investigação foi pautado na pesquisa-ação de Thiollent e Barbier, de cunho dialógico e interventivo. $\mathrm{O}$ lócus foi uma turma do BB Educar em São Sebastião (DF). Constatou-se que a aprendizagem da leitura e da escrita contribuiu para mudanças na forma de ser, pensar e agir dos educandos que, na sua percepção, empoderaram-se, tornaramse referência para a comunidade e seus filhos mais novos, passando a adotar uma postura metacognitiva, ou seja, refletindo sobre o seu processo de aprendizagem, compreendendo a sua forma singular de pensar e ampliando estratégias de raciocínio para apreensão da realidade e resolução de problemas.

Palavras-chave: Educação de Jovens e Adultos; Alfabetização. Aprendizagem. Desenvolvimento.

Maria Clarisse Vieira - Doutora em Educação pela Universidade Federal de Minas Gerais (UFMG). Professora do Programa de Pós-graduação em Educação da Universidade de Brasília (UnB). Coordenadora do Grupo de Ensino-Pesquisa-Extensão em Educação Popular e Estudos Filosóficos e Históricos Culturais (UnB). Email:<mariaclarissev@ gmail.com>.

Luciana de Oliveira Pinto - Mestre em Educação pela Universidade de Brasília (UnB). Membro do Grupo de Ensino-Pesquisa-Extensão em Educação Popular e Estudos Filosóficos e Histórico-Culturais (UnB).

Email: <luciana200000@terra.com.br $>$. 


\section{LEARNING AND DEVELOPMENT OF YOUTH AND ADULT ALPHABETIZATION FROM A HISTORICAL-CULTURAL APPROACH}

ABSTRACT: This article presents the results of research that aimed to investigate the contributions that the learning of reading and writing provides for the development of young people and adults, as well as the meanings they attribute to their alphabetization process, based on the historical-cultural approach of Bakhtin, Vigotski and Leontiev and the materialism historical and dialectic of Marx and Engels. The methodological procedure of the investigation in reference was based on the action research of Thiollent and Barbier, with a dialogical and interventional character. The locus was a group of BB Educar in São Sebastião (DF). It was found that the learning of reading and writing contributed to changes in the way of being, thinking and acting of students who, in their perception, have become empowered, a reference for the community and their younger children, adopting a metacognitive posture, that is, reflecting on their learning process, understanding their unique way of thinking and expanding strategies of reasoning for apprehension of reality and problem solving. Keywords: Youth and Adult Education. Alphabetization. Learning; Development.

\section{INTRODUÇÃO}

O Currículo em Movimento do Distrito Federal (GDF/SEDF, 2014b) reconhece a Educação de Jovens e Adultos (EJA) como uma modalidade da educação básica destinada ao atendimento de jovens, adultos e idosos da classe trabalhadora que, ao longo da sua história, não iniciaram ou interromperam sua trajetória escolar. Em seus Pressupostos Teóricos (GDF/SEDF, 2014a), o referido documento preconiza que a escola tem a função de garantir a aprendizagem de todos os estudantes, por meio de processos educativos de qualidade. Para que isso ocorra, é fundamental o reconhecimento da prática social e da diversidade do educando. As Diretrizes Operacionais (GDF/ SEDF, 2014c), por seu turno, reconhecem o direito à aprendizagem ao longo da vida e a necessidade de ser assegurado o acesso à escolarização a qualquer tempo, em qualquer idade e em qualquer condição. Para tanto, reitera a necessidade de serem estabelecidas estratégias para atender, de forma diversa, sujeitos em diferentes condições de aprendizagens, respeitando assim as especificidades e realidades da EJA. No tocante à alfabetização, a VI Conferência 
Internacional de Educação de Adultos (UNESCO, 2010) ressalta que o direito à alfabetização é um pré-requisito para desenvolver o empoderamento pessoal, social, econômico e político.

Adentrando à discussão, Galvão e Di Pierro (2013) enfatizam que o pensamento social dominante na atualidade atribui papel relevante à alfabetização pelo valor que a leitura e a escrita adquiriram nas sociedades urbano-industriais, eminentemente grafocêntricas e permeadas pela ciência e tecnologia. Oliveira (2001), por sua vez, realça a questão da singularidade dos alfabetizandos jovens e adultos, que se constituem em sujeitos únicos não só no que tange à sua trajetória de vida, como também ao seu funcionamento psicológico, encarado como um processo em constante transformação. Vargas e Gomes (2013) salientam a existência de modos singulares de ser jovem e de ser adulto, pois ao longo da história cada indivíduo constrói seu psiquismo e recria a cultura numa complexa interação entre pessoas, objetos, símbolos e significados. Nesse processo, a escolarização ocupa lugar de destaque e desencadeia o desenvolvimento de funções psicológicas e novas identidades.

As contribuições acima se alinham ao objetivo central do presente artigo, qual seja, apresentar os resultados de investigação que buscou identificar e analisar as contribuições e significações da aprendizagem da leitura e da escrita no âmbito de uma turma de alfabetização de jovens e adultos do Programa BB Educar em São Sebastião (DF). Metodologicamente, a investigação teve cunho qualitativo, nos moldes da pesquisa-ação proposta por Thiollent (2011) e Barbier (2007), que se caracteriza por ser um modelo aberto e dialético, que se organiza em torno de sujeitos, e não objetos, visando uma mudança social e pessoal cujos resultados podem contribuir, de forma permanente, no cotidiano do grupo pesquisado. Ao longo do processo investigativo, foram adotadas as técnicas da observação participante, diário de campo, rodas de conversa e entrevistas.

Estruturalmente, o texto está dividido em quatro seções. $\mathrm{Na}$ primeira são analisados os princípios teóricos que nortearam a pesquisa: materialismo histórico e dialético de Marx e Engels, e abordagem histórico-cultural de Bakhtin, Vigotski e Leontiev. $\mathrm{Na}$ segunda é discutida a proposta pedagógica do BB Educar e, na seção seguinte, a práxis vivenciada e os resultados obtidos no que tange às mudanças engendradas e aos significados pessoais atribuídos pelos educandos ao seu processo de alfabetização. Por fim, na quarta seção são apresentadas as considerações finais relativas à investigação analisada ao longo deste artigo. 


\section{ABORDAGEM HISTÓRICO-CULTURAL}

Para Marx e Engels (2009), o trabalho constitui-se no salto evolutivo que permite a transformação da realidade natural em realidade cultural. Isso ocorre quando o homem produz instrumentos, age intencionalmente sobre a natureza e constrói suas próprias condições de existência. Ao transformar a natureza, através da atividade coletiva, o homem não apenas produz bens materiais, como também a si mesmo e a suas relações sociais. A história humana é, pois, a história da relação dialética do homem com a natureza e com os seus pares, tendo como base o processo de produção da vida imediata. Nesse contexto, o homem não é entendido como um ser universal e abstrato, mas historicamente situado, que na produção social da própria vida contrai relações de produção, que correspondem a uma etapa determinada de desenvolvimento das suas forças produtivas materiais. Assim, o modo de produção da vida material "condiciona o processo em geral de vida social, político e espiritual. Não é a consciência dos homens que determina seu ser, mas, ao contrário, é o seu ser social que determina sua consciência” (MARX, 1996, p. 52). A consciência, entretanto, não é uma "consciência pura", pois:

\footnotetext{
O "espírito" tem consigo de antemão a maldição de estar "preso" à matéria, a qual nos surge aqui na forma de camadas de ar em movimento, de sons, numa palavra, da linguagem. A linguagem é tão antiga quanto a consciência - a linguagem é a consciência real prática que existe também para outros homens e que, portanto, só assim existe também para mim. E a linguagem só nasce, como a consciência, da necessidade, da necessidade orgânica de intercâmbio com outros homens. (...) A consciência é, pois, logo desde o começo, um produto social e continuará a sêlo enquanto existirem homens (MARX e ENGELS, 2009, p. 43-44).
}

Desse modo, a função da linguagem é representar o que há na consciência dos homens e estabelecer vínculos de comunicação entre eles, de tal forma que consciência e linguagem se permeiam em uma relação dialética, na qual o homem sofre influência da linguagem ao relacionar-se socialmente e, concomitantemente, a influencia quando altera a realidade por suas atitudes e ações conscientes.

Tendo como base o princípio marxista de que consciência e linguagem são produtos sociais, Bakhtin (2014, p. 35) afirma que "não basta colocar face a face dois homo sapiens quaisquer para que os signos se constituam. É fundamental que esses dois indivíduos estejam socialmente organizados, que formem um grupo: só assim um sistema de signos pode constituir-se". Isso implica que o signo e a situação social estão intrinsecamente ligados, pois todo signo é 
ideológico, assim como tudo o que é ideológico pode ser identificado como um signo, ou seja, possui um significado e remete a algo que está situado fora de si mesmo. Nesse contexto, a consciência individual é um fato socioideológico, que adquire forma e existência nos signos criados por um grupo organizado no curso de relações sociais. A lógica da consciência, por sua vez, é a lógica da comunicação ideológica, da interação semiótica de um grupo social. A existência do signo é, dessa forma, a materialização da comunicação social e a palavra é o fenômeno ideológico por excelência, pois a realidade da palavra é totalmente absorvida por sua função de signo. Embora a realidade da palavra, como a de qualquer outro signo, resulte do consenso entre indivíduos, Bakhtin (2014) observa que uma palavra é, ao mesmo tempo, produzida pelos próprios meios do indivíduo. Isso implica o papel da palavra como material semiótico da vida interior, da consciência, do discurso interior. A palavra, portanto, perpassa todas as relações entre indivíduos, sendo tecida a partir de fios ideológicos que servem de trama a essas relações em todas as suas instâncias. Ela existe na realidade concreta, na realidade viva da língua e não em estado de dicionário, pois:

Em toda enunciação, por mais insignificante que seja, renova-se sem cessar essa síntese dialética viva entre o psiquismo e o ideológico, entre a vida interior e a vida exterior. (...) Sabemos que cada palavra se apresenta como uma arena em miniatura onde se entrecruzam e lutam os valores sociais de orientação contraditória. A palavra revela-se, no momento da sua expressão, como produto da interação viva das forças sociais (BAKTHIN, 2014, p. 67).

Esse embate pela palavra é decorrente do confronto de interesses sociais nos limites de uma mesma comunidade semiótica num dado momento histórico, uma vez que classes sociais distintas se utilizam de uma mesma língua. Consequentemente, em todo signo ideológico confrontam-se índices de valor contraditório, o que torna o signo vivo e móvel, capaz de transformar-se de forma contínua. Ao conceber o signo ideológico como instrumento social entre os homens, Bakhtin (2003) mostra que a consciência só pode ser interpretada à luz desse mesmo signo. Nesse caso, o homem se constitui no encontro com outros homens, mediado pelo material semiótico proveniente da interação social.

Partindo do princípio de que a relação do homem com o mundo é mediada por sistemas simbólicos socialmente construídos, Vigotski (2007) postula que o indivíduo, a partir de sua experiência com o mundo objetivo e da sua relação interpessoal concreta com os seus pares socialmente organizados, internaliza as formas culturalmente 
estabelecidas de funcionamento psicológico e constrói o seu sistema de signos. Essa construção é um processo contínuo e dialético, na medida em que o sistema de signos por ele internalizado é alvo de permanente significação e ressignificação subjetiva, pois o homem é um agente ativo que uma vez influenciado pela cultura na qual está inserido, modifica-se e, uma vez modificado, age em relação a cultura que o modificou, modificando-a. Nesse contexto, a cultura não é vista como algo estático ao qual o indivíduo se submete, porquanto os seus membros estão num constante movimento de recriação e reinterpretação subjetiva de informações, conceitos e significados.

Dessa forma, é através da internalização dos meios de operação das informações, historicamente determinados e culturalmente organizados, que a natureza social das pessoas torna-se igualmente sua natureza psicológica, com a linguagem exercendo um papel preponderante. Vigotski (2009) observa que a linguagem e o pensamento possuem trajetórias independentes e distintas, ou seja, o pensamento inicialmente é não verbal e a linguagem não intelectual. Porém, num determinado momento da sua trajetória, o pensamento torna-se verbal e a linguagem racional, iniciandose uma profunda transformação no funcionamento psicológico humano, pois a linguagem fornece os conceitos e as formas de organização do real que constituem a mediação entre o sujeito e o objeto do conhecimento. No plano do desenvolvimento filogenético da espécie, foi a necessidade de intercâmbio durante o trabalho que impulsionou a vinculação dos processos de pensamento e linguagem. Na ontogênese, ou seja, no desenvolvimento do indivíduo, esse impulso é dado pela sua inserção num determinado grupo social. Em ambos os casos, a confluência das trajetórias do pensamento e da linguagem é fundamental para o desenvolvimento humano, pois quando isso ocorre a natureza do próprio desenvolvimento se transforma, do biológico para o sócio-histórico, uma vez que:

O pensamento verbal não é uma forma natural e inata de comportamento, mas uma forma histórico-social e por isso se distingue basicamente por uma série de propriedades e leis específicas, que não podem ser descobertas nas formas naturais do pensamento e de linguagem. Mas a conclusão principal é a de que, ao reconhecermos o caráter histórico do pensamento verbal, devemos estender a essa forma de comportamento todas as teses metodológicas que o materialismo histórico estabelece para todos os fenômenos históricos da sociedade humana (VIGOTSKI, 2009, p. 149).

Ao aprender a se utilizar da linguagem, o ser humano é capaz de pensar de uma forma que não seria possível se ela não existisse, pois a generalização e a abstração só se dão pela linguagem. Mas o uso da linguagem como instrumento do pensamento supõe um processo de internalização, ou seja, não é apenas por falar com as outras pessoas que 
o indivíduo dá um salto qualitativo para o pensamento verbal. Assim, na sua gênese, além da função de comunicação, o indivíduo também desenvolve, gradualmente, a chamada "fala egocêntrica", que é um diálogo alto consigo mesmo, numa tentativa de organização verbal coerente do pensamento. Com o tempo, a "fala egocêntrica" transformase em "discurso interior", ou seja, uma forma totalmente interna da linguagem, sem vocalização externa. Vigotski (2009) ressalta que é na palavra que se encontra a unidade das duas funções básicas da linguagem: intercâmbio social e pensamento generalizante. A palavra, por seu turno, possui dois componentes: significado e sentido. O significado consiste na definição corrente e relativamente estável da palavra, partilhada por todos os interlocutores. O sentido, por sua vez, refere-se ao significado para cada indivíduo, constituindo-se numa formação dinâmica e complexa, que está relacionada às vivências afetivas e ao contexto de uso da palavra. Assim, o pensamento nunca é igual ao significado direto das palavras, pois para comunicar-se, as pessoas têm de operar com palavras dentro de seu significado dicionarizado, mas ao fazer isso, o pensamento original é modificado e sentidos pessoais são perdidos. Os pensamentos só podem ser compreendidos a partir de um exame das forças fundamentais que os causaram: as emoções, impulsos, necessidades e motivações, que são subjetivos e estão em constante processo de transformação. A relação entre pensamento e palavra é, pois, um "processo vivo de nascimento do pensamento na palavra” (VIGOTSKI, 2009, p. 484). O vínculo entre o pensamento e a palavra não é um vínculo primário, dado de uma vez por todas. Ele surge no desenvolvimento e ele mesmo se desenvolve. A palavra é o estágio supremo do desenvolvimento do homem, uma vez que "ela não esteve no princípio. No princípio esteve a ação. A palavra constitui antes o fim que o princípio do desenvolvimento. A palavra é o fim que coroa a ação.” Faz-se necessário, então, analisar o início, ou melhor, a gênese do desenvolvimento humano, procurando identificar o papel desempenhado pela aprendizagem ao longo desse processo.

Vigotski (2014) postula que desenvolvimento e aprendizagem são processos interdependentes e que, ao longo da vida, o indivíduo constrói o seu psiquismo a partir da interação entre os planos filogenético e ontogenético. Dessa forma, nascido com as características filogenéticas da espécie e constituído a partir das ações e relações sociais travadas com os seus pares, cada indivíduo segue o caminho da ontogênese a partir dos artefatos concretos e simbólicos, das formas de significação e das visões de mundo fornecidas pelos grupos culturais em que se encontra inserido. Além disso, a pluralidade de conquistas psicológicas que ocorrem ao longo da vida 
gera complexos processos de desenvolvimento, que será singular para cada sujeito. Não obstante o percurso do desenvolvimento ser em parte definido pelo processo filogenético de maturação, é o processo de aprendizagem que impulsiona e viabiliza, em última instância, a construção do psiquismo. O aprendizado começa desde os primeiros dias de vida, a partir da interação com as pessoas mais próximas, inicialmente no nível externo, social, cultural e interpsíquico e, na sequência, a partir da sua significação e internalização, ocorre a sua ressignificação, num nível interno, psicológico e intrapsíquico.

Quanto ao desenvolvimento, Vigotski (2014) ressalta que é fundamental distinguir dois níveis: o efetivo e o potencial. O primeiro refere-se ao nível de desenvolvimento das funções psicointelectuais que se atingiu como resultado de um processo específico de desenvolvimento já realizado. Entretanto, este nível não indica completamente o estado de desenvolvimento, uma vez que o indivíduo pode realizar, com a ajuda de outrem, um grande número de ações que supera os limites da sua capacidade atual. Desse modo, a diferença entre as tarefas realizáveis com o auxílio de terceiros e as tarefas que podem desenvolver-se de forma autônoma define a zona de desenvolvimento potencial. A fim de tornar-se mais efetiva e provocar mudanças, a aprendizagem deve ocorrer de forma sistematizada e formal, no âmbito de instituições escolares, agindo diretamente na zona de desenvolvimento potencial (ZDP), ou seja, deve envolver conteúdos ainda não conhecidos, mas passíveis de compreensão a partir da ajuda de colegas e professores. Dessa forma, "o único bom ensino é o que se adianta ao desenvolvimento" (VIGOTSKI, 2014, p. 114). Importante observar que a aprendizagem, mesmo na ZDP, não gera automaticamente desenvolvimento, pois “ $\mathrm{O}$ processo de desenvolvimento não coincide com o da aprendizagem, o processo de desenvolvimento segue o da aprendizagem, que cria a área de desenvolvimento potencial" (VIGOTSKI, 2014, p. 116).

Leontiev (1978a, p. 13), discípulo de Vigotski, aprofunda a análise da relação entre aprendizagem e desenvolvimento explicitando o conceito de atividade como a forma de relação mediada do homem com o mundo, dirigida por motivos e fins a serem alcançados, ou seja, constituise em um "processo que é eliciado e dirigido por um motivo - aquele no qual uma ou outra necessidade é objetivada. Em outras palavras: por trás da relação entre atividades, há uma relação entre motivos". O sujeito, dessa forma, orienta-se por objetivos, agindo de forma intencional por meio de ações planejadas, imerso num sistema de relações sociais, onde o trabalho coletivo ocupa um lugar central e supõe a existência de uma 
divisão técnica de funções. Assim, a atividade é uma forma complexa de relação do homem com o mundo, que envolve finalidades conscientes e atuação coletiva e cooperativa. Entretanto, a vida:

Não é simplesmente a soma das diferentes espécies de atividade. Alguns tipos de atividade são, numa dada época, dominantes e tem uma importância maior para o desenvolvimento ulterior. (...) Razão porque devemos dizer que o desenvolvimento do psiquismo depende não da atividade em seu conjunto, mas da atividade dominante. (LEONTIEV, 1978b, p. 292).

Isso posto, ele entende por atividade dominante ou principal não necessariamente a mais frequente, mas sim aquela que enseja o surgimento de outros tipos de atividade, na qual processos psíquicos particulares tomam forma e são reorganizados, impulsionando novas aprendizagens e mudanças psicológicas no indivíduo. A forma como a vida material é construída influencia o conteúdo dessas atividades. Embora haja um caráter periódico no desenvolvimento psíquico, esta periodicidade não é absoluta, universal e cronológica, visto que:

A influência das condições históricas concretas exerce-se tanto sobre o conteúdo concreto do estágio dado do desenvolvimento, como sobre o curso do processo de desenvolvimento psíquico no seu conjunto. Assim se explica porque a duração e o conteúdo do período de desenvolvimento que se poderia chamar de preparação do homem para a participação na vida social do trabalho, a duração e o conteúdo da educação e do ensino, nem sempre tenham sido os mesmos historicamente (LEONTIEV, 1978b, p. 294).

Cada época da vida é caracterizada por uma atividade principal. Assim, o desenvolvimento é impactado pela alteração desta atividade e, em consequência, do lugar que o indivíduo ocupa no sistema das relações sociais. A periodização do desenvolvimento segue um processo cuja origem provém do contexto social, ocorrendo por meio das trocas da atividade dominante em cada ciclo. Essa troca decorre de alterações na esfera motivacional desse sujeito, orientando-o para uma nova direção e ensejando mudanças na relação entre atividade principal, demais atividades, ações e procedimentos. Tais mudanças, por sua vez, alteram a hierarquia das atividades e geram, por conseguinte, um processo de reorganização psíquica e novas aprendizagens que impulsionam o desenvolvimento humano, de forma contínua e permanente.

A partir desse arcabouço teórico, nas seções seguintes serão analisadas a proposta pedagógica do Programa BB Educar; a práxis vivenciada na turma de São Sebastião (DF); as contribuições que a aprendizagem da leitura e da escrita propiciou ao desenvolvimento dos educandos; e o significado pessoal por eles atribuído ao seu processo de alfabetização. 


\section{PROPOSTA PEDAGÓGICA DO PROGRAMA BB EDUCAR}

O Programa BB Educar surge, em 1994, no âmbito do Banco do Brasil, a partir de parceria com o CEPAFRE (Centro de Educação Paulo Freire de Ceilândia), no Distrito Federal, inicialmente para a alfabetização de seus funcionários e, posteriormente, colocado a serviço da comunidade, em âmbito nacional. Ele visa à alfabetização de jovens e adultos, tendo como base o princípio de que "uma nação só tem um resultado mais efetivo em relação a essa problemática quando a sociedade civil - cidadãos, instituições e empresas - participa e exige que o Estado cumpra o seu papel" (FBB, 2004, p. 9). Em 2000, o programa passa a ser gerenciado pela Fundação Banco do Brasil, a partir do seu vetor educação, e ao longo do tempo "tem assumido princípios e diretrizes históricas com ênfase na perspectiva da alfabetização como ato político de libertação dos sujeitos e de transformação social" (FBB, 2004, p. 9). Verifica-se, dessa forma, que o BB Educar enquadra-se nas políticas de responsabilidade social de uma fundação vinculada a uma empresa do setor financeiro e está à margem do sistema regular de ensino, possuindo, portanto, um caráter não oficial e não certificatório, que o Programa reconhece e, por conseguinte, cobra do Estado brasileiro uma participação mais efetiva na Educação de Jovens e Adultos.

A linha político-pedagógica do Programa (FBB, 2007) tem como base a concepção de aprendizagem e desenvolvimento de Vigotski e os princípios de uma educação dialógica e libertadora de Freire, assumindo um enfoque que é, ao mesmo tempo: histórico, no qual sujeito e conhecimento são instâncias inacabadas, em permanente construção; social, pois aprendizagem e desenvolvimento são mediados pelo outro e pelo social, uma vez que indivíduo e sociedade são instâncias interdependentes; e cultural, na medida em que ensinar e aprender influenciam e são influenciados por um conjunto de práticas, instituições e ordens simbólicas por meio das quais os homens se relacionam entre si e com a natureza.

Em decorrência, a concepção de ser humano subjacente é de um ser histórico, crítico, criativo e inacabado que "constrói as próprias condições de existência e transforma a realidade, ao mesmo tempo em que se transforma influenciado pelas condições espirituais e materiais do meio em que vive" (FBB, 2007, p. 9). A educação é vista como um processo ativo e dialético de construção do saber, que pressupõe o permanente diálogo entre quem aprende e quem ensina, entre o 
conhecimento e o contexto. Alfabetizar, portanto, não é ensinar o educando a repetir palavras, mas sim a dizer a sua palavra, criadora de cultura, libertadora e organicamente vinculada a sua realidade de vida.

Nesse sentido, Freire (1987) salienta que o importante na alfabetização de jovens e adultos é a aprendizagem da leitura e da escrita como um ato político e criador que envolve, necessariamente, a compreensão crítica da realidade. Por isso, uma educação que vise à emancipação humana deve ser desveladora e instigar o educando a questionar a realidade a sua volta e analisar criticamente o contexto no qual a palavra é construída, qual seja, uma sociedade capitalista, historicamente situada, na qual forças sociais antagônicas lutam pela hegemonia dos seus conceitos e valores. O objetivo do BB Educar, portanto, não é apenas ensinar a ler e escrever, mas sobretudo estimular nos alunos uma reflexão sobre a realidade na qual estão inseridos, com vistas a sua transformação em prol de melhores condições de vida para toda a comunidade.

\section{PRÁXIS VIVENCIADA}

A práxis analisada teve como referência uma turma de alfabetização do BB Educar, formada por 19 educandos de São Sebastião (DF), cujas aulas ocorreram de 16.08.16 a 01.07.17, duas vezes por semana, das $18 \mathrm{~h} 30$ às $21 \mathrm{~h} 30$, no total de 231 horas/aula. Na referida pesquisa foram priorizados, para fins de observação e entrevista, os alunos mais assíduos e que tiveram um período maior de aprendizagem e convivência com os colegas e educadores: ACI, EMB, MAB, MGRR e RS, denominados educandos-foco. Importante ressaltar que as atividades desenvolvidas foram filmadas com a anuência por escrito dos educandos, que autorizaram também a citação dos seus nomes e a divulgação das conversas e depoimentos do grupo em publicações acadêmicas. Não obstante a autorização concedida a partir de um Termo de Consentimento lido, discutido e assinado por eles, optou-se por identificá-los neste artigo apenas pelas iniciais do seu nome.

O trabalho pedagógico desenvolvido pautou-se pela dialogicidade e, dessa forma, as questões discutidas ao longo do curso, que serviram de referência para o processo de aprendizagem, tanto no âmbito da língua portuguesa como da matemática, história e geografia, foram escolhidas pela própria turma, a partir de rodas de conversa. Nos dois primeiros meses trabalhou-se o tema da identidade, com o intuito de estabelecer um clima de confiança e 
viabilizar a discussão acerca da motivação dos educandos em relação à retomada dos estudos; sua história de vida e expectativas em relação ao futuro; bem como características históricas, culturais e geográficas da sua cidade e região de origem.

$\mathrm{Na}$ sequência, com o grupo mais coeso e unido, os educandos identificaram as principais situações-problemas-desafios enfrentadas pela comunidade e, no bojo da discussão de cada uma delas, produziram cartazes e textos coletivos alusivos às adversidades vivenciadas, bem como cartas endereçadas ao administrador regional contendo sugestões para sua superação. Nessas rodas de conversa, todos tiveram a oportunidade de defender seus pontos de vista, num processo de construção da palavra própria. Dessa forma, não se buscava o consenso: abria-se espaço para o confronto das singularidades, num clima de profundo respeito e aceitação mútua. Os trabalhos desenvolvidos foram fruto desse diálogo e a partir deles foram trabalhadas a grafia das palavras, a estruturação das frases e a autoestima dos educandos que, ao final, descobriram-se capazes de sistematizar, de forma crítica e reflexiva, a sua leitura de mundo. Nesse contexto, a temática discutida embasava a alfabetização matemática, a partir da resolução de problemas com a ajuda de elementos concretos que, gradativamente, cediam lugar a cálculos mais abstratos. Até o término do primeiro semestre, em 08.12.16, foram trabalhadas cinco situações-problemas-desafios: saúde, segurança, violência nas escolas, educação e preconceito.

$\mathrm{Na}$ retomada das aulas, em 31.01.17, os educandos iniciaram a discussão relativa ao transporte e saneamento básico. Em seguida, compilaram as sete cartas até então elaboradas, que continham as propostas de superação das situações-problemas-desafios priorizadas, e a entregaram ao administrador regional de São Sebastião, em 20.03.17, num encontro realizado na sede da Administração. Uma vez fechado esse ciclo de discussões, a turma manifestou interesse em debater questões de âmbito nacional, tais como as reformas trabalhista e previdenciária e a operação Lava Jato. Nessa etapa, os temas foram debatidos a partir da leitura coletiva de textos veiculados na internet, jornais e revistas. Após a discussão inicial, cada educando criava, escrevia no quadro e lia para os seus colegas uma frase ou parágrafo que sintetizava o seu sentimento em relação à questão para, na sequência, ser efetuada a sua correção coletiva. Semanas antes do término do curso, a turma visitou o Congresso Nacional, palco de deliberações acerca das reformas debatidas em sala de aula. Durante a visita, houve a descoberta de que é um espaço 
aberto à população, que pode acompanhar as sessões em galerias ao lado do plenário. Por fim, em 01.07.17, ocorreu a formatura da turma, com a entrega dos certificados e a apresentação à comunidade dos trabalhos desenvolvidos.

Ao longo do curso, constatou-se que o processo de alfabetização dos educandos-foco foi heterogêneo, em função da singularidade de cada um, fruto das diferentes experiências, vivências e histórias de vida. Essa constatação é aderente ao questionamento de Vigotski (2000, p. 33): "O que é o homem? Para Hegel é o sujeito lógico. Para Pavlov é soma, organismo. Para nós, é a personalidade social, o conjunto de relações sociais encarnado no indivíduo". Dessa forma, o indivíduo, a partir da sua relação interpessoal no âmbito social e concreto, internaliza formas culturalmente estabelecidas de funcionamento psicológico no âmbito intrapsicológico. Assim, se por um lado os educandos-foco constituem um coletivo social historicamente situado, que nasceu em cidades do interior regidas por relações de produção capitalista, cresceu no seio de famílias oprimidas da classe trabalhadora, iniciou ainda criança a vida laboral e não teve condições de concluir o ensino fundamental anos iniciais, por outro possuem singularidades próprias, por estarem inseridos em múltiplos e distintos grupos sociais, que formam a base da sua teia de relações, que é única, peculiar e forma a sua estrutura psicológica, que é dinâmica e em permanente processo de construção. Na condição de construtores da sua psique, são sujeitos da sua aprendizagem e possuem motivações, estratégias e significações distintas em relação a esse processo.

No tocante à motivação, RS comentou que a retomada dos estudos teve como mote aprender coisas novas e manter-se lúcida, ativa e feliz, aos 84 anos. Já para MGRR a motivação maior foi gerenciar o orçamento doméstico, até então monopolizado pelo seu marido. Isso a incomodava, pois não tinha acesso às correspondências e contas que chegavam à sua casa. EMB, por seu turno, tinha interesse em participar de cursos de leitura bíblica na igreja que frequentava e ter acesso a novos conhecimentos. MAB, por sua vez, queria ajudar seu filho mais novo, de 10 anos, e não precisar recorrer aos vizinhos sempre que ele tinha dúvidas em seus deveres escolares, bem como aprimorar-se no trabalho e poder ler as bulas e controlar, com maior precisão, os remédios tomados pelos idosos que cuidava. Por fim, além do desejo de aprimorar-se no seu trabalho de mecânico automotivo, ACI tinha também como prioridade auxiliar o seu filho mais novo, de 8 anos, na escola e incentivar o seu filho mais velho, de 17 anos, a continuar seus estudos na EJA. 
Com relação ao processo de aprendizagem da leitura e da escrita, MAB observou que ele "abriu a sua mente" pois, na sua percepção:

\begin{abstract}
MAB: Meu modo de pensar mudou, e muito. A gente muda até o jeito de falar, a gente aprende a falar porque está descobrindo o mundo da leitura, aprendendo outras coisas também na vida da gente, e as pessoas fazem as perguntas e você sabe responder. Então isso mudou a minha forma de pensar, e muito. (...) Eu sinto que quando a gente aprende a gente pega mais confiança, e eu sinto essa mudança. Antes quando ia fazer um negócio, a gente até fazia certo, mas ficava em dúvida: Será que está certo? Mas agora, como a gente está abrindo a mente, a gente vai devagarzinho e cada dia que vai passando vai tendo mais confiança. Assim, vai entendendo melhor, porque se você ficar com a mente fechada você não entende $o$ que é que aquela pessoa está te falando. Mas quando você estuda você abre a mente (...) porque quanto mais você entende uma coisa mais vai entendendo a outra.
\end{abstract}

No entendimento de MAB, a aprendizagem da leitura e da escrita efetivamente gerou mudanças na sua forma de ser, pensar e agir, porque lhe deu mais confiança em externar os seus pontos de vista e se posicionar. Além disso, percebeu que uma aprendizagem leva a outra, ou seja, é um processo contínuo que ocorre ao longo da vida. Quanto à estratégia por ela adotada, percebeu-se que a fala egocêntrica acompanhava a escrita, e era utilizada para organizar o pensamento. Quando perguntada por que falava enquanto escrevia, respondeu:

\footnotetext{
MAB: Porque eu penso muito rápido, aí eu quero escrever também rápido. Quando eu falo alto, vou escutando e pensando as letras. Vou lendo, mas vou escutando e pensando as letras e colocando. Aí fica mais fácil, isso facilita e muito, porque você vai encaixando as letras na memória. (...) Só na mente eu não consigo. Eu tenho que ficar falando porque aí é que vêm as letras na memória, porque se você ficar só caladinha, não consegue, não sai.
}

Isso indica que ela, ao se deparar com dificuldades na aprendizagem da escrita, desenvolvia processos de significação socializados consigo mesmo, uma vez que a escuta do som da palavra a ajudava a estruturar o pensamento e a raciocinar de forma mais clara. Estratégia semelhante era utilizada por MGRR, ao reconhecer que "eu sou igual a MAB. Se eu ficar só assim calada... só meu nome que eu faço calada, porque eu já sei, mas o resto eu preciso falar do mesmo jeito que a MAB." Dessa forma, observou-se que a fala egocêntrica, caracterizada por Vigotski (2009) como processo de transição entre a fala social e o discurso interior, no caso de MAB e MGRR funcionava como facilitadora do processo de aprendizagem da escrita. Mas essa estratégia não se mostrou unânime. Quando perguntado se utilizava estratégia semelhante, ACI comentou: "não, eu já escrevo calado, só pensando. Já dou conta de escrever... eu vejo as letras... pensando e escrevendo... eu vou lendo, falo a palavra na mente e escrevo". 
Analisando as suas histórias de vida, verificou-se que MAB estudou de forma intermitente até os 15 anos, interrompendo os estudos no $3^{\circ}$ ano do ensino fundamental após engravidar. Retornou a escola na EJA, aos 22 anos, mas logo em seguida parou em função da gravidez do seu segundo filho. Já MGRR frequentou a escola até o $1^{\circ}$ ano, interrompendo os estudos aos 9 anos por imposição da avó, que precisava dela para cuidar dos afazeres domésticos e da sua saúde, que se deteriorou após um derrame. ACI, por sua vez, cursou até o $4^{\circ}$ ano e frequentou a escola até os 17 anos. Não foi adiante por falta de interesse, não obstante a insistência do pai para que priorizasse os estudos. Esses dados poderiam induzir à conclusão precipitada de que MAB e MGRR, por possuírem menos tempo de estudo e menor escolaridade, recorriam à fala egocêntrica como estratégia de aprendizagem da escrita, enquanto ACI não o fazia em função do seu maior tempo de estudo e escolaridade. Essa suposição, entretanto, perde força na medida em que se constatou que EMB, que estudou até o $3^{\circ}$ ano e interrompeu os estudos aos 15 anos em função do casamento, não se utilizava dessa estratégia, nem tão pouco RS, que estudou apenas até o $1^{\circ}$ ano em função da necessidade de ajudar a mãe na roça. Ao longo das aulas, entretanto, observou-se que EMB e RS solicitavam constantemente o auxílio de colegas e das educadoras durante a produção de textos, de modo que, ao se depararem com dificuldades na aprendizagem, recorriam imediatamente a terceiros, sem procurarem antes, de forma mais sistemática e persistente, sanar dúvidas a partir de estratégias como da fala egocêntrica, adotada por MAB e MGRR, ou da fala interior, por ACI.

Quanto às mudanças engendradas, todos foram unânimes em apontá-las, independente da motivação ou estratégia adotada. Dessa forma, ao refletirem sobre o seu processo de alfabetização, os educandos-foco tiveram a percepção de que ocorreram transformações no seu modo de ser, pensar e agir, ressaltando que a aprendizagem da leitura e da escrita foi uma atividade priorizada neste período, de tal forma que gradativamente extrapolou o ambiente escolar e passou a ocorrer em todos os espaços sociais, integrada às demais atividades cotidianas. Essa percepção da parte deles, que priorizaram a aprendizagem da leitura e da escrita nesse período, coaduna-se com a teoria de Leontiev (1978b), segundo a qual cada período da vida é caracterizado por uma atividade principal. Assim, o desenvolvimento é impactado pela alteração desta atividade, cuja troca decorre de alterações na esfera motivacional, orientando os sujeitos para uma nova direção e ensejando mudanças na relação 
entre atividade principal, demais atividades, ações e procedimentos. Tais mudanças geram um processo de reorganização psíquica e novas aprendizagens, que impulsionam o desenvolvimento dos indivíduos e geram transformações e mudanças na sua forma de ser, pensar e agir.

Nesse sentido, a fim de facilitar a análise, as mudanças identificadas pelos educandos-foco da presente pesquisa foram agrupadas em quatro categorias: empoderamento, referência comunitária, referência familiar e metacognição, discutidas a seguir:

a) Empoderamento

Ao longo do processo de alfabetização os educandos debateram, num clima de profunda confiança e cooperação, as principais situações-problemas-desafios da comunidade, bem como questões de âmbito nacional que os impactava, como as reformas trabalhista e previdenciária. Nas rodas de conversa, foram chamados a se expressar e, dessa forma, romper o silenciamento. Esse falar, ressalta Reis (2011, p. 71), "leva ao domínio da oralidade, à descoberta do poder de falar e que esse poder falar significa ter poder. Poder expor-se, confrontar-se e confrontar, transformar e ser transformado". Além disso, leva também à descoberta do pensar consigo mesmo, do pensar com os outros e da consciência de que:

\footnotetext{
Pensar não é pensar o que o professor pensa, o patrão manda, o chefe ordena, o superior estabelece, ou simplesmente consumir o conhecimento conhecido ou tido como culto. Mas que pensar é produzir o próprio pensar (intrapessoalidade) na relação com o outro (interpessoalidade), como resultante da relação com o outro, e não exclusivamente decorrente do outro. Enfim, a constituição de um ser de conhecimento, um ser epistemológico (REIS, 2011, p. 72).
}

Essa consciência ficou patente durante a entrega da carta ao administrador regional, com os educandos se posicionando de forma ativa e reflexiva, ocorrendo, inclusive, alguns embates, como quando MAB comentou que "a saúde está péssima. Desculpe falar, mas está péssima”. E o administrador, já se eximindo de qualquer responsabilidade, retrucou: "Pode falar, porque eu não sou o culpado... eu não sou o culpado”. Em outra ocasião, ao ler as propostas de superação das situações-problemas-desafios apontadas pela turma e relacionar a falta de médicos a falhas no processo seletivo dos cursos de medicina, foi contestado por ACI:

Administrador: A gente teria que ter, no País, um programa para formar mais médicos. Essa dificuldade de entrar na universidade... o vestibular é muito difícil, porque como ele tem um processo de triagem... o processo de seleção tinha de ser mais provocativo... e no decorrer do curso identificar quem vai para frente e quem tem de cair fora, para a gente poder ter mais médicos. 
ACI: Mas o problema não é o Estado? Médico tem muito. („) O problema não é o Estado que não dá condições para eles trabalharem?

Além disso, quando o administrador comentou o pulso firme da sua gestão em relação ao desvio de recursos, ACI posicionou-se criticamente e solicitou uma cópia da gravação da conversa para ter em mãos o registro desse compromisso e, futuramente, poder cobrar, caso necessário, o seu efetivo cumprimento:

Administrador: Se, por exemplo, vocês fossem três empresários e eu falasse assim: preciso construir uma praça, mas eu estou sem arquiteto para fazer o projeto, você vem com o projeto já prontinho para mim, porque sabe que eu vou direcionar a obra para você. Aí você ganha a primeira obra, a outra obra ele ganha e a terceira obra o outro ganha, e cada um de vocês dá um percentual para o administrador. É assim que funciona em muitos lugares. Só que aqui não... se desviar um centavo eu meto na cadeia, chamo a policia e o pau quebra.

ACI: Essa cópia aí eu quero, do que você falou agora... Se sair um centavo você bota a pessoa na cadeia... essa copia eu quero da gravação.

Ao solicitar a cópia, ACI externa a sua desconfiança em relação aos seus governantes, passando a cobrar diretamente deles o cumprimento das suas promessas de lisura no trato com os recursos públicos. Além disso, na avaliação final do curso, MAB e ACI comentaram que, na sua percepção, que é comungada pelos demais educandos-foco, o encontro foi relevante por terem conhecido o administrador e conversado de igual para igual com ele:

MAB: Foi muito importante a gente conhecer o nosso administrador... a gente nem conhecia. Foi importante porque se a gente precisar já sabe onde ele está, já sabe o caminho certo. E foi importante porque a gente conversou de igual para igual... e falamos com ele sobre os problemas da nossa cidade. Agora ele está sabendo dos nossos problemas. Vamos ver agora se ele melhora isso ou vai ficar somente na conversa... vamos ver a diferença aí.

ACI: Acho também que foi muito importante, como a MAB falou, a gente conhecer o administrador... a administração. Eu moro aqui há mais de 20 anos e nunca tinha entrado na administração... e agora nós entramos e tivemos a oportunidade de conversar de igual para igual com o administrador.

Dessa forma, percebe-se que eles perderam o receio de se reportar a alguém que ocupa um cargo de destaque e, gradativamente, a relutância e o medo de discutir os seus pontos de vista foram superados. Além disso, MAB deixa claro que, no seu entender, é a população quem conhece os reais problemas da comunidade e não as autoridades que, muitas vezes, não os vivenciam no dia a dia. Assim, ao dessilenciaremse e falarem a sua palavra própria, os educandos-foco empoderaramse e efetivamente mudaram a sua postura em relação ao mundo e as 
pessoas que os cercam. Consequentemente, deram o primeiro passo no sentido de constituírem-se em sujeitos de amor, por respeitarem, ajudarem e acolherem os seus colegas e, ao mesmo tempo, serem por eles respeitados, ajudados e acolhidos; sujeitos de poder, por posicionarem-se criticamente, reivindicarem seus direitos, lerem, discutirem e escreverem a sua palavra própria; e sujeitos de saber, por construírem conhecimento práxico a partir da sua vivência concreta aliada à leitura de textos e debates nos ambientes sociais nos quais estão inseridos.

b) Referência comunitária

Esse empoderamento, que faz com que os educandos-foco superem o sentimento de subalternidade, leva-os a adotar uma postura ativa e a buscar, de alguma forma, auxiliar as pessoas que ainda não se libertaram desse estigma. Nesse sentido MAB, em seu discurso de formatura, ao colocar-se como exemplo de superação, tem como objetivo inspirar as pessoas que buscam a realização de sonhos aparentemente inatingíveis:

MAB: quando cheguei aqui fui engatinhando, devagarzinho e fui aprendendo as palavras, saber ler os textos que vocês viram aí que a gente fez... é um pouquinho difícil... não é fácil... a gente trabalha o dia todo, chega em casa tem de cuidar da casa, cuidar de filho, cuidar de marido e vir para a escola... é difícil... mas graças a Deus eu consegui ficar até o final... gente, se vocês tiverem um sonho, não desistam... vocês vão passar por muitas barreiras, mas não desistam nunca de sonhar... se eu consegui ficar aqui até hoje, vocês conseguem também.

Percepção correlata possui EMB que, prestes a iniciar o curso de leitura bíblica na igreja que frequenta, comentou:

EMB: Vai ser diferente, porque no BB Educar a gente discutia as dificuldades, os problemas da comunidade, como a segurança, a educação, tudo isso... mas o importante é a gente ir sempre vivendo e aprendendo. E isso que a gente discutiu lá acrescentou demais na minha vida, eu me desenvolvi muito, porque às vezes a gente mesmo é que se acha tão rebaixado assim, tão atrasado... aquela pessoinha. E agora não, a gente aprende que nós somos iguais, que não tem diferença nenhuma. (...) $\mathrm{E}$ eu vou passar essa minha experiência para os meus novos colegas.

Assim, ela vai iniciar o curso buscando, por um lado, ser uma referência para os novos colegas e repassar para eles a experiência adquirida ao longo da vida e, em especial, durante o curso de alfabetização do BB Educar e, por outro, mostrando-se aberta a novas aprendizagens, que certamente ocorrerão no decorrer do seu desafio de empreender uma leitura mais aprofundada da bíblia. MGRR também se coloca como referência ao comentar que:

MGRR: Eu acho que para as outras turmas melhorarem, as pessoas têm de vir a todas as aulas para poder aprender, porque se não vier todo dia a pessoa só aprende a metade 
e não sabe o que foi feito para trás. Se todo mundo vier todo dia, não faltar nenhum dia, então aprende. (...) Nós que viemos todo dia, a gente já sabe como é a caminhada... o que foi que passou, o que não passou... então tem de fazer como a gente fez.

Assim, verifica-se que ela se coloca como parâmetro por ter sido, ao longo das aulas, assídua e cooperativa com os colegas e, ao seu término, ter a percepção de que alcançou o seu objetivo de utilizar-se socialmente da leitura e da escrita e que está preparada para assumir novos desafios. Nesse sentido, em uma conversa posterior, sinalizou positivamente quanto a possibilidade de vir a atuar como monitora numa próxima turma. No tocante a RS, interessante notar que ela não se percebe como tal, porém é aclamada pelos demais educandos como um exemplo a ser seguido, não apenas pelo desenvolvimento alcançado ao longo do seu processo de alfabetização, mas principalmente por reconhecerem que nunca é tarde para aprender. MAB traduz bem esse reconhecimento: "Eu falo assim para o meu pai: tem uma aluna lá na minha escola que é mais velha, que tem oitenta e poucos anos... Aí ele: nossa, é mesmo? Aí eu falo: pois é, nunca é tarde." A esse respeito, RS ressaltou que se sentia muito feliz pela oportunidade que estava tendo e que, na sua percepção, chegou em boa hora:

\footnotetext{
RS: Falando também com meu filho (...) aí ele disse: ah, agora está estudando. Eu disse: eu estou meu filho... agora já na minha idade... agora que eu estou gozando a minha infância... agora que deu certo de estudar.

Luciana: Porque a senhora não teve infância?

RS: Não, não tive... de jeito nenhum.
}

Dessa forma, apesar de decana da turma, RS sentia-se ainda jovem e com muita disposição para aprender e renovar-se sempre. Por conseguinte, não é de estranhar que os demais educandos comentassem que se RS, aos 84 anos conseguiu se alfabetizar e, dessa forma, adquirir novos conhecimentos e ampliar a sua visão de mundo, eles que são bem mais jovens do que ela também conseguirão. E isso servia de estímulo e motivação para todos.

c) Referência familiar

Além de referência comunitária, os educandos-foco tiveram a percepção de que haviam também se tornado referência para familiares que necessitavam de estímulo para retomar ou intensificar os estudos, notadamente seus filhos mais novos. Nesse sentido o filho mais novo de MAB comentou que o fato da sua mãe estar se alfabetizando o incentivou muito na escola:

Luciana: A sua mãe estar aqui aprendendo incentivou você também na escola? Filho de MAB: Incentivou muito, porque eu vejo a luta dela. (...) 
MAB: E ele melhorou muito na escola. (...) porque no ano passado ele estava com falta de interesse mesmo. Agora quando eu entrei aqui ele melhorou bastante, a professora até elogiou ele foi muito... as letrinhas dele melhoraram bastante. Quando ele chega em casa ele mesmo pega o caderno e faz os deveres... ele mesmo tenta fazer sozinho. Eu acho que ele pensou assim: se a minha mãe consegue... e a correria da minha mãe... ela chega aqui do serviço e vai. Eu faço isso para ajudar ele também, porque isso também motivou.

Dessa forma, o fato de MAB voltar a estudar influenciou o seu filho em dois aspectos: do ponto de vista cognitivo, a dedicar-se mais a escola e ao seu processo de aprendizagem; e do ponto de vista emocional, o fez sentir-se mais acolhido e protegido pela mãe, que passou a ajudá-lo nos deveres de casa, sem precisar mais pedir a ajuda de terceiros, que nem sempre se mostravam dispostos a auxiliá-lo. ACI compartilha desse sentimento, na medida em que também percebe que se transformou numa referência positiva, que incentiva seus filhos a dedicarem-se mais aos estudos e permanecerem na escola:

Luciana: E o que é que melhorou agora que você está no curso ACI? Tem ajudado na sua relação com o seu filho mais novo?

ACI: Tem ajudado bastante. Ele já está na terceira série e todo dia está indo para a escola, não é como eu que venho apenas duas vezes por semana. E a criança, mesmo estando conhecendo agora, pega as coisas mais rápido do que um adulto... pega mais rápido. Então ele tem evoluído muito esse período e eu estou tentado dar o exemplo, acompanhar e ajudar ele. (...)

Luciana: E você sentiu que com o seu filho mais velho você ter voltado a estudar estimulou ele também na escola?

ACI: Estimulou bastante... ele vê a gente interessado... e eu também cobro muito dele nesse ponto porque o que eu quero para mim, eu quero melhor ainda para os meus filhos... porque eu tive a oportunidade e eu também estou dando a ele a oportunidade para estudar e não parar.

Observa-se que existem, conforme destacado por Schmelkes (1996, p. 17), efeitos intergeracionais na atividade educativa envolvendo jovens e adultos, na medida em que se estabelece uma clara "relación entre la escolaridad de los padres y la escolaridade que alcanzam los hijos". Assim, a retomada dos estudos por MAB e ACI reverbera positivamente na escolaridade dos seus filhos, que se sentem motivados a avançar no seu processo de aprendizagem, por sentirem que dispõem de maior apoio familiar. Ir para a escola passa a ter uma significação muito mais contundente para esses adolescentes que, ao testemunharem a luta e o esforço dos seus pais em seu processo de alfabetização, reconhecem que não devem desperdiçar a oportunidade que estão tendo e que seus progenitores, por inúmeras razões, não tiveram em sua infância ou, se a tiveram, não deram o valor devido naquele tempo em função de uma série de fatores e contingências. 


\section{d) Metacognição}

Vigotski (2009) destaca a relevância da aprendizagem escolar, por propiciar o acesso a novos conhecimentos que de alguma forma extrapolam os conceitos espontâneos, ou seja, a vivência cotidiana, e por abarcarem conceitos científicos e ainda mais abstratos que viabilizam, por sua vez, a compreensão dos seus próprios processos mentais. Nesse sentido, o conceito científico é um instrumento simbólico, uma faculdade do pensamento para fazer mediação cognitiva no conhecimento da realidade e, por isso, suplanta o contexto perceptivo imediato:

O conceito científico pressupõe seu lugar definido no sistema de conceitos, lugar esse que determina a sua relação com os outros conceitos. Marx definiu com profundidade a essência de todo conceito científico: "se a forma de manifestação e a essência das coisas coincidissem imediatamente, toda ciência seria desnecessária". Nisto reside a essência do conceito científico. Este seria desnecessário se refletisse o objeto em sua manifestação externa como conceito empírico (VIGOTSKI, 2009, p. 293-294).

Dessa forma, todo conceito científico faz parte de um sistema e só existe em relação a outros conceitos. Assim, formar conceitos é a capacidade de reunir enunciados verdadeiros a respeito da realidade e a sua internalização significa o domínio de ferramentas culturais, possibilitando melhor conhecimento sobre as suas operações psicológicas, pois:

A tomada de consciência se baseia na generalização dos próprios processos psíquicos, que redunda em sua apreensão. Neste processo manifesta-se, em primeiro lugar, o papel decisivo do ensino. Os conceitos científicos, com sua relação inteiramente distinta com o objeto, mediados por meio de outros conceitos, com seu sistema hierárquico interior de inter-relações, são o campo em que a tomada de consciência dos conceitos, ou melhor, a sua generalização e a sua apreensão parecem surgir antes de qualquer coisa. (...) Desse modo, a tomada de consciência passa pelos portões dos conceitos científicos (VIGOTSKI, 2009, p. 290).

Ao longo do curso, observou-se que essa consciência foi gradativamente se aprofundando, na medida em que os educandosfoco passaram a adotar uma postura metacognitiva, ou seja, a refletir sobre o seu próprio processo de aprendizagem, analisando e procurando compreender a sua forma singular de pensar, com o intuito de reconhecer, questionar e ampliar as suas estratégias de raciocínio para apreensão da realidade e resolução de problemas. Dessa forma, respeitadas as singularidades de cada um, os educandosfoco perceberam a importância da reflexão acerca do seu processo de aprendizagem e a abertura permanente a novos conhecimentos, adquiridos a partir dos seus conceitos espontâneos. 


\section{CONSIDERACְ̃̃ES FINAIS}

A práxis vivenciada com a turma do BB Educar de São Sebastião, especialmente com MGRR, MAB, ACI, EMB e RS, sujeitos da pesquisa objeto deste artigo, longe de esgotar o debate, viabilizou a elaboração de algumas considerações relevantes no que tange à contribuição da aprendizagem da leitura e da escrita ao desenvolvimento de jovens e adultos e aos significados por eles atribuídos ao seu processo de alfabetização. Nesse sentido, verificou-se que os educandos-foco entendiam a alfabetização como a aprendizagem e o uso social da leitura e da escrita e acreditavam que a sua importância estava ligada, principalmente, ao fato de viabilizar maior autonomia na consecução das tarefas cotidianas e, por conseguinte, fortalecer a autoestima e a motivação para o estudo, viabilizando novas aprendizagens e uma compreensão mais crítica do mundo. Além disso, reconheciam também que contribuía para o aperfeiçoamento profissional, a ampliação das oportunidades de trabalho e a melhoria da qualidade de vida. Eles chegaram a esse entendimento a partir da reflexão acerca do seu processo de alfabetização, que se mostrou heterogêneo, em função da singularidade de cada um, fruto das diferentes vivências e histórias de vida. Não obstante a sua singularidade, eles foram unânimes em apontar a aprendizagem da leitura e da escrita como uma atividade prioritária nessa etapa da sua vida, que contribuiu sobremaneira para o seu desenvolvimento cognitivo e emocional. No decorrer do curso, reportaram-se a mudanças percebidas na sua forma de ser, pensar e agir, que foram agrupadas em quatro categorias: empoderamento, referência comunitária, referência familiar e metacognição, esta última relacionada ao fato de que, ao adotarem uma postura reflexiva em relação ao seu processo de aprendizagem, passaram a compreender a sua forma peculiar de pensar e, com isso, ampliaram as suas estratégias de raciocínio com vistas à apreensão da realidade e resolução de problemas. Ao longo desse processo coletivo de reflexão, aprendizagem e mudança, dessilenciaram-se e perderam o medo de expor as suas ideias e proferir a sua palavra própria. Sentiram-se, no decorrer da sua alfabetização, empoderados, capazes de conversar de igual para igual com as demais pessoas, inclusive aquelas de maior escolaridade e poder aquisitivo, que eventualmente ocupassem cargos de maior notoriedade, uma vez que superaram o estigma de inferioridade que o sistema capitalista impinge àqueles que não tiveram a oportunidade de priorizar a escola na sua infância e juventude. Além disso, vislumbraramse também como referência para a comunidade, pois uma vez retirado o véu da subalternidade que encobria o seu potencial criador, passaram 
a adotar uma postura mais ativa e a buscar, de alguma forma e a partir dos meios ao seu alcance, auxiliar as pessoas a sua volta que ainda não haviam se libertado desse estigma ideologicamente imposto. Esse auxílio tornou-se mais contundente quando envolveu parentes mais próximos que precisavam de estímulo e apoio para continuar os estudos. Assim, ao perceberem-se também como referência familiar, passaram a estabelecer uma estreita parceria com seus filhos mais jovens. Desse modo, verificouse que a EJA reverberou na Educação Infantil e no Ensino Fundamental, na medida em que a aprendizagem da leitura e da escrita por parte dos pais viabilizou o estudo conjunto com seus filhos e provocou mudanças em ambos, que passaram a agir de forma proativa em busca de novos conhecimentos e soluções para os problemas que afetam não só a eles como à comunidade na qual estão inseridos.

\section{REFERÊNCIAS}

BAKHTIN, M. Estética da criação verbal. São Paulo: Martins Fontes, 2003.

BAKHTIN, M. Marxismo e filosofia da linguagem: problemas fundamentais do método sociológico da linguagem. São Paulo: Hucitec, 2014.

BARBIER, R. A pesquisa-ação. Brasília: Liber Livro, 2007.

FBB - Fundação Banco do Brasil. Programa BB Educar: Apostila do alfabetizador. Brasília, 2004.

FBB - Fundação Banco do Brasil. Programa BB Educar: Diário do Alfabetizador. Brasilia, 2007.

FREIRE, P. Pedagogia do Oprimido. Rio de Janeiro: Paz e Terra, 1987.

GALVÃO, A.; DI PIERRO, M. Preconceito contra o analfabeto. São Paulo: Cortez, 2013.

GDF/SEDF - Governo do Distrito Federal/Secretaria de Educação. Currículo em Movimento da Educação Básica: Pressupostos teóricos. Vol. 1. Brasília, 2014a.

GDF/SEDF - Governo do Distrito Federal/Secretaria de Educação. Currículo em Movimento da Educação Básica: EJA. Vol. 6. Brasília, 2014b.

GDF/SEDF - Governo do Distrito Federal/Secretaria de Educação. Diretrizes Operacionais da EJA 2014-2017. Brasília, 2014c.

LEONTIEV, A. Atividade, consciência e personalidade. Marxist Internet Archive, 1978a. LEONTIEV, A. O desenvolvimento do psiquismo. Lisboa/Portugal: Livros Horizonte, 1978b. MARX, K. Para a Crítica da economia política. São Paulo: Nova Cultural, 1996. 
MARX, Kl; ENGELS, F. A Ideologia Alemã. São Paulo: Expressão Popular, 2009.

OLIVEIRA, M. K. Jovens e adultos como sujeitos de conhecimento e aprendizagem. In: RIBEIRO, V. (org.). Educação de Jovens e Adultos: novos leitores, novas leituras. São Paulo: Ação Educativa, 2001.

REIS, R. A constituição do ser humano: amor-poder-saber na educação/alfabetização de jovens e adultos. Campinas: Autores Associados, 2011.

SCHMELKES, S. Las necesidades básicas de aprendizaje de los jóvenes y adultos en América Latina. In: OSORIO, J.; RIVERO, J. (org.). Construyendo la modernidad educativa em América Latina: Nuevos desarrollos curriculares em la educación de personas jóvenes y adultas. Lima/Peru: OREAL-UNESCO:CEAAL: Tarea, 1996.

THIOLLENT, M. Metodologia da Pesquisa-ação. São Paulo: Cortez, 2011.

UNESCO. Confintea VI - Sexta Conferência Internacional de educação de adultos Marco de Ação de Belém. Brasília, 2010.

VARGAS, P.; GOMES, M. Aprendizagem e desenvolvimento de jovens e adultos: novas práticas sociais, novos sentidos. Educação e Pesquisa, v. 39, n. 2, 2013.

VIGOTSKI, L. Psicologia concreta do homem. In: PUZIREI. L. S. Vigotski: Manuscrito de 1929. Educação e Sociedade, ano XXI, n. 71, Jul 2000.

VIGOTSKI, L. Formação social da mente. São Paulo (SP): Martins Fontes, 2007.

VIGOTSKI, L. Construção do pensamento e da linguagem. São Paulo: Martins Fontes, 2009.

VIGOTSKI, L. Aprendizagem e desenvolvimento na idade escolar. In: VIGOTSKI L.; LURIA, A.; LEONTIEV, A. Linguagem, desenvolvimento e aprendizagem. São Paulo: Ícone, 2014.

Submetido: 07/03/2018

Aprovado: 01/03/2019

Contato:

Maria Clarisse Vieira Faculdade de Educação Universidade de Brasília Campus Universitário Darcy Ribeiro Brasilia |DF| Brasil CEP 70.910-900 